\title{
A ARTE DA CATIRA \\ Negócios e reprodução familiar de sitiantes mineiros
}

\author{
Eduardo Magalhães Ribeiro \\ Flávia Maria Galizoni
}

\section{Catiras}

Ao final do século XIX, Karl Kautsky escrevia que raros profissionais conheciam $\mathrm{O}$ comércio tão bem quanto os camponeses. Eles acompanhavam as flutuações dos muitos mercados em que entravam com sua produção diversificada, e a negociação com tantos vendedores e compradores gerava um conhecimento preciso, que dificilmente seria igualado por grandes produtores ou especialistas em comércio.

Na literatura, João Guimarães Rosa escreveu quase o mesmo no conto Corpo fechado, em que narrava as aventuras de Manuel Fulô que, por vingança, negociara com uns ciganos dois cavalos imprestáveis como se fossem animais da melhor qualidade. Ele engordou, ensaiou e enfeitou os

Artigo recebido em dezembro/2005

Aprovado em março/2007 cavalos para fazer a barganha diante dos olhos dos moradores do arraial e mostrar que era, realmente, especial na arte da catira. ${ }^{1}$

Como esses, existem centenas de exemplos do conhecimento que sitiantes têm dos mercados e de como sabem fazer valer seus trunfos quando podem ganhar num negócio. Esse pequeno movimento de trocas, regido por normas próprias e pouco articulado aos mercados nacionais, é vital para gerar, conservar e ampliar sua renda. A lógica peculiar desses negócios explica atitudes que desconcertam técnicos e pesquisadores: para que recriar bezerros se a Cooperativa compra somente o leite? Para que criar porcos se não há produção de milho? Por que gastar em bens duráveis de consumo o apurado na migração? Essas atitudes fazem parte de estratégias bem concertadas, levadas a cabo no correr de anos, às vezes para apoiar a colocação profissional do filho, para ampliar o terreno familiar, para liberar a esposa 
de parte do trabalho doméstico e acrescentar uma trabalhadora parcial à lavoura.

O objetivo deste artigo é investigar a lógica e o propósito dessas trocas, denominadas catiras em quase todo o estado de Minas Gerais. Analisa-se por que são tão recorrentes esses negócios garantidos por relações de confiança, em que são investidas as beiradas, que criam, aos poucos, os patrimônios materiais e simbólicos desses sitiantes.

\section{Trocas e estratégias}

O tema da catira surgiu de maneira periférica em diversas pesquisas de campo entre 1985 e 2004. Entrevistados abordavam o assunto entre risadas e evasivas, insistiam em reduzir sua importância e regularidade, referiam-se aos negócios como tradição, e a sua ritualidade ocultava os interesses materiais. Mas a freqüência com que o tema aparecia nas pesquisas e na prática dos entrevistados impôs sua relevância. A idéia deste artigo surgiu com a refocalização de cadernos de campo e a releitura de subtextos de autores consolidados, que revelaram a importância dessas pequenas trocas que ocupam muito do cotidiano de sitiantes. Este estudo partiu, assim, de pesquisas realizadas com outros propósitos em áreas rurais do Norte, Noroeste, Sudoeste, e, particularmente, Zona da Mata (municípios de Espera Feliz, Muriaé e, sobretudo, Miradouro), Alto Paranaíba (municípios de Rio Paranaíba, Campos Altos e São Gotardo), Mucuri e Oeste de Minas Gerais (municípios de Araújos, Moema e, principalmente, Bom Despacho). Tudo indica que nessas regiões de pecuária leiteira mais ativa existem mais catiras ou, pelo menos, são encontrados mais especialistas no assunto.

Nos cerrados do Oeste mineiro, no Alto São Francisco, foram pesquisados oitenta produtores integrados à Cooperativa Agropecuária de Bom Despacho, que respondeu na década de 1990 pela maior produção leiteira do estado. Nessa região havia uma grande fragmentação das unidades de produção - com média de 28 hectares, variando entre 12 e 97 hectares -, a produção leiteira distribuía-se harmonicamente entre os grupos de áreas, incluindo as glebas menores, e o trabalho familiar dominava em todas as explorações. As entrevistas trataram de produção, terra, produtividade do rebanho, família e geração de renda.

Outra parte das informações veio de entrevistas com quarenta produtores atingidos pela expropriação dos 60 mil hectares, para a implantação do Programa de Assentamento Dirigido do Alto Paranaíba - Padap, que até os anos de 1990 foi a estrela do agronegócio no cerrado. Sitiantes das terras desconsertadas - a topografia acidentada das vertentes dos chapadões - explicaram como remontaram seus sistemas de produção depois do estabelecimento do Padap para se reproduzir à margem da integração agroindustrial que se constituíra em norma cultural.

A terceira fonte importante de dados foi criada na pesquisa com quinze sitiantes, plantadores de café, feijão e criadores de gado, das ladeiras esconsas da Zona da Mata mineira. Neste caso, os pesquisadores permaneceram doze meses na comunidade camponesa, registrando histórias e estratégias que surgem no encontro produtivo dos homens com a terra.

Mais tarde, outras pesquisas agregaram dados a essas fontes originais e, com mais alguma observação participante, a catira pôde começar a ser pensada como uma prática que ocupava um lugar definido, tornando-se objeto de consulta em textos que foram relidos para conformar um marco teórico, impreciso ainda, que se situa na fronteira difusa entre antropologia, sociologia e economia rural.

A base bibliográfica deste artigo, então, veio de uma observação já clássica de Schultz (1965) sobre o tradicionalismo rural. O autor criticava a identificação, freqüente e insensata, entre pobreza e irracionalidade: a pobreza, escreveu, não levaria o agricultor a organizar sua unidade de produção de forma irracional; pelo contrário, a ameaça da escassez estimula a gestão criteriosa dos parcos bens e recursos, inclusive um planejamento rigoroso e de longo prazo que tenderia a ser eficiente no horizonte de possibilidades postos à sua disposição.

Essa lição de Schultz indica que é vital compreender a lógica dessas sociedades rurais. Foi seguindo essa sugestão que tantos autores conseguiram explicar a dinâmica própria e as relações específicas que parte do meio rural mantém com a sociedade inclusiva, pois a ação econômica dos 
agricultores tradicionais - ressalvada a ambigüidade do conceito - tem por propósito reproduzir família e terra; ela ordena recursos culturais, humanos, materiais e naturais num conjunto de ações coerentes, denominadas estratégias de reprodução, que compreendem desde a inserção nas companhias integradoras (Santos, 1978; Lovisolo, 1989) até o planejamento do consumo familiar (Heredia, 1979; Brandão, 1981); desde o ciclo emigratório para formar patrimônio (Garcia Jr., 1989; Woortmann, 1990) até o uso regulado dos recursos naturais (Almeida, 1988; Godoy, 1998); e, ainda, a exclusão planejada de herdeiros (Moura, 1978; Galizoni, 2002) ou a incorporação das atividades não-agrícolas (Amaral, 1988; Schneider, 2001). Sempre, porém, serão estratégias marcadas pela junção de fatores disponíveis, recombinando recursos que seriam inúteis noutras sociedades rurais. ${ }^{2}$

Assim, é possível perceber que esses agricultores não mantêm apenas uma relação passiva com os mercados. Pelo contrário, produzem constantemente minúsculas estratégias de convívio, que variam de acordo com situações, regiões, condições de acesso aos recursos, cultura e economias locais. Recursos, conhecimentos e oportunidades definem um conjunto particular de alternativas, a partir das quais são construídos os arranjos específicos de negócios que cada coletividade efetivamente pode executar.

As possibilidades que conformam os arranjos são, ao mesmo tempo, singulares e plurais, e as estratégias econômicas emergem de um mesmo conjunto de variáveis combinadas de maneira muito diversas. Assim, fluxos de renda podem surgir de migração sazonal, integração agroindustrial, pluriatividade, programas públicos, feiras locais ou pequenos negócios, mas sitiantes de um lugar tendem a privilegiar mais algumas atividades do que outras. As escolhas são balizadas por circunstâncias, conhecimentos e recursos materiais, naturais, sociais e simbólicos -, que se combinam de maneiras diferentes para criar situações novas que reproduzem, renovadamente, os mesmos sujeitos.

Porém, comércio, dinheiro e liquidez ocupam um lugar central nessas estratégias, mesmo quando os mercados estão em posição secundária na hierarquia de valores da sociedade rural. A lógica das relações tradicionais pode se articular aos mercados, como mostrou Maria Sylvia de Carvalho Franco (1974). Investigando o comércio de café no século XIX paulista, a autora observou que o dinamismo do negócio se devia aos laços pessoais que uniam fazendeiros e comissários de café. As relações sociais de proximidade - que autorizavam ao comissário vender café sem consultar o produtor, e davam ao produtor o crédito para sacar dinheiro sem ter colhido o café agilizavam os negócios. A confiança cimentava as relações econômicas e lastreava a circulação de mercadorias.

Confiança e reciprocidade são a base dos negócios nas sociedades tradicionais, o que garante o acesso ao crédito (Santos Filho, 1957), à terra (Martins, 1981) e à rede de trocas (Garcia, 1984). A importância dos mercados é mediada pela ética camponesa (Woortmann, 1987), e os negócios são animados por relações de proximidade (Abramovay, 2004).

Nessas comunidades rurais há pouca circulação monetária e nem sempre os bens são trocados por dinheiro; mais freqüentemente, as trocas se baseiam em animais, bens de valor estável e aceitação generalizada. Os animais constituem, portanto, o mealheiro, base do acúmulo e do pecúlio familiar. ${ }^{3}$

A literatura a esse respeito revela que as estratégias são formuladas para garantir a reprodução e, secundariamente, a ampliação do patrimônio; mostra também que, com base na confiança e na reciprocidade, são as circunstâncias que constroem moedas e mercados específicos. Assim, é possível compreender as catiras: pautadas por cálculos de longo prazo, cimentadas por relações sociais costumeiras, mediadas por um pecúlio vivo, formam um conjunto miúdo e contínuo de trocas de bens de pequeno valor que influem decisivamente no comércio de regiões rurais e, portanto, na sua dinâmica.

\section{Os negócios}

Na economia dos sitiantes de Minas Gerais, não é somente a produção agropecuária que amplia o patrimônio familiar, ou pode-se afirmar que isso raramente ocorre. Por uma série de 
razões - exclusão setorial política e econômica, canais precários de circulação mercantil, condição subordinada na negociação -, a produção garante o sustento, mas não a ampliação da riqueza. A lavoura de mantimentos e/ou a integração agroindustrial asseguram os alimentos; a produção de café e/ou a integração agroindustrial pagam as contas corriqueiras da família - roupas, remédios, energia etc. -, mas a expansão do patrimônio familiar vem de atividades que estão à margem da produção agropecuária regular.

Na Zona da Mata, os pagamentos feitos pela indústria garantem a mantença e o custeio dos integrados da avicultura, mas seu ganhame é gerado no comércio de subprodutos, cama-de-frango e leite. Os sitiantes dessa região e, também, do Sul de Minas Gerais produzem mantimentos, pagam as contas com a venda de café, mas acumulam bens com o pequeno comércio. Nos sítios do Alto Paranaíba, o pecúlio forma-se em períodos de trabalho temporário em fazendas ou com parcerias em lavouras. No Norte e Nordeste, amealha-se com a migração sazonal; no Sudoeste e parte do Oeste, mais integrados, os sitiantes ganham com a indústria a domicílio; artesanato ou atividades urbanas costumam gerar os excedentes no Centro e no Campo das Vertentes; os produtores de leite no Oeste mineiro mantêm-se com a integração, mas fazem renda com venda de bezerro ${ }^{4}$

Em suma, nas mais diferentes regiões, os sitiantes formam seu patrimônio segundo um cálculo de longo prazo que difere de um para outro, mas perseguem, sempre, quatro metas de aquisição bem definidas:
1. Bens de uso generalizado e negociação fácil, como utensílios domésticos, eletrônicos e automóveis.

2. Animais de valor, como porcos, cavalos ou vacas.

3. Partes da herança partilhada pelos pais: lotes de cunhados de um dos esposos, ou, quando isto não é possível, terrenos urbanos.

4. Terrenos rurais de não-membros da família. ${ }^{5}$

Os meios usados para alcançar tais metas variam, mas sempre incluirão o trabalho migração sazonal, pluriatividade e parceria, que produzem rendas fora da produção agrícola da unidade familiar -, os repasses - como aposentadorias e bolsas, que produzem rendas independentemente do esforço familiar - e, finalmente, os negócios - que no decorrer do tempo transformam em patrimônio os subprodutos e os bens periféricos amealhados. A reprodução pode ser ampliada pela terra, por criame de gado ou pelas relações de trabalho, quando, por exemplo, a parceria gera um a-mais para o parceiro-proprietário. Escolher um ou outro método depende do regime agrário e das conjunturas; a lógica, porém, sempre é a mesma, apresentada de maneira esquemática no Quadro 1.

Essa estrutura de gestão dos bens e das fontes de recursos familiares foi resumida na frase definitiva de um sitiante de Miradouro, Estevão Dias: "Roça é comida, lavoura é dinheiro, gado é negócio". Ele explica, didaticamente, que a roça de mantimentos, ou lavoura branca, provê o alimento; que a venda do café (lavoura, nesse caso, deve ser sempre entendida como lavoura de café)

\section{Quadro 1}

Demandas e Fontes de Recursos Materiais para Sitiantes Mineiros

\begin{tabular}{|ll|l|}
\hline \multicolumn{2}{|c|}{ Demandas } & \multicolumn{1}{c|}{ Fontes de suprimento ou destinação } \\
\hline 1. & Sustento alimentar & $-\quad$ Lavoura branca ou de mantimentos; integração agroindustrial \\
\hline 2. & Despesa da família e custeio do sítio & $-\begin{array}{l}\text { Lavoura de café; integração agroindustrial; feiras; ocupações não-agrícolas; } \\
\text { migrações sazonais; programas sociais }\end{array}$ \\
\hline 3. & Renda líquida (sobrescrito ou ganhame) & $-\begin{array}{l}\text { Subprodutos da integração; ocupações não-agrícolas; migrações sazonais; } \\
\text { parcerias; negócios }\end{array}$ \\
\hline 4. & Patrimonialização & $-\quad$ Gado bovino; automóveis; terrenos urbanos; terrenos rurais \\
\hline
\end{tabular}

Fonte: Pesquisas de campo. 
paga as contas da casa e o custeio da produção, mas que a renda que dará forma ao patrimônio advem fatalmente dos negócios.

Para os sitiantes, essas fontes não se confundem. Eles costumam diferenciar rigorosa, didática e eticamente as origens dos recursos, inclusive para avaliar a evolução do patrimônio. Mesmo pequenos acréscimos têm origem num determinado crédito, o que é evidente em frases como "este carro veio de uma panha de café", "esta égua veio na troca de uns leitões" e "este terreno aumentado veio da venda de uma ponta de gado". Assim, como o patrimônio se forma com ações independentes da produção imediata de alimentos, ele é considerado uma riqueza construída à margem, porque expande sem sacrificar o consumo familiar. E, com exceção dos recursos advindos de migrações sazonais e ocupações não-agrícolas, o crescimento da riqueza é creditado em parte à "natureza mesma das coisas", pois surge apartado da lida concreta na roça familiar. É como se fosse um capital mágico, já que o patrimônio cresce pela mediação do meio natural: a lavoura que produz seus frutos - que são antes de tudo produtos da própria terra; a terra que subordina o parceiro e acrescenta renda ao seu próprio preço - aparentemente por ser terra e não pelas relações sociais que a envolvem; o gado criado solto que aumenta em peso, bezerros e negócios. Seria apenas mágica, não fosse a interferência do cálculo humano, de um lado, e da catira, de outro: o cálculo governa a lida e rege a catira; a catira dá forma material ao recurso criado à margem da produção de mantimentos e o converte, lentamente, em patrimônio. A catira cria um fluxo de reconversão contínua que, às vezes, consome uma vida para dar forma patrimonial a um cálculo humano.

É por isso que catira - ou barganha, breganha, baldroca, negócio, rolo: as denominações são muitas - é uma das instituições mais sólidas do meio rural mineiro. Trata-se da troca de animais por bens de consumo, produtos agrícolas, dinheiro ou um pouco de cada, e vice-versa. Em algumas regiões é um negócio bastante freqüente e os negociadores são extremamente dedicados; em Minas Gerais serve para dispor bens sem serventia, trocar o miúdo pelo remediado e este pelo graúdo, para encorpar, aos poucos, os bens que compõem o patrimônio familiar.
Catira, então, o leitor já percebeu, não é um negócio qualquer, mas, uma troca essencial. A ritualidade, o respeito aos costumes e às culturas conformam os atos, o cenário, a coreografia e o palco onde o cálculo humano é executado. As trocas têm por base a confiança e o nome dos parceiros, são marcadas pelas histórias pessoais, carecem de muita conversa e, às vezes, de uma encenação emprestada ao jogo do truco, mesmo quando, desde o começo, todos já saibam qual será o desfecho do negócio.

As catiras nascem de bases materiais já dadas: apartação de bezerro-de-ano, milho no paiol, uma bicicleta, leitões engordando, um Chevette encostado, vacas niquentas - dessas que nunca amansam, que parecem esconder no corpo uma nica, ou moeda de níquel, daí o nome. Há, sempre, o quê negociar: "Tudo dá negócio...", gostava de dizer Itamar de Mattos, criador de gado, mensageiro da Palavra, plantador de café, meio-negociante lá do Miradouro. E negócios surgem até de encontros que parecem acidentais:

Ele estava nesta égua e eu ia passando com um milho para levar para os porcos. Ele falou que apreciava muito uns capadinhos. E ainda falou: "Sabe que dá prejuízo sustentar porco com milho da gente? Porco come é do nosso suor...". Aí eu senti que ele queria era negociar, mas eu não sabia direito era o que eu queria conseguir dele. E aí eu falei, falei mais é para valorizar o que é meu: "Eu fui criado com gordura de porco e nunca que acostumei com óleo". Dai começou... (José Nelson, sitiante da Zona da Mata).

Então, deram-se a troca dos porcos pela égua, a parição da égua e a catira do potro, a produção das leitoas e novas, e encadeadas, séries de trocas, porque fêmeas dão vida às trocas, desde aquelas originárias, de irmãs por terra que são a base física e genética da reprodução dos sítios -, até aquelas outras, rotineiras, que conduzem para o sítio os bichos-fêmeas e levam o sitiante à prosperidade, porque a sabedoria ensina que "é bicho que urina para trás que bota o dono para a frente". No entanto, mulheres raramente fazem catiras, que estão muito ligadas ao papel e à representação masculina. ${ }^{6}$

Os preços que correm no mercado nacional são apenas balizas para as catiras. Elas são mar- 
cadas, sobretudo, pelas peculiaridades locais e por um horizonte limitado de benefícios, de forma que se tornam um jogo onde ganham todos os que se reconhecem: os que sabem a utilidade do bem que recebem, os que adivinham o destino do produto que dispõem. Por isso esse tipo de barganha é, também, um jogo regulador do patrimônio e da fortuna - uma redistribuição, conforme definiu Mauss -, porque realoca os bens nas parcelas necessárias para cada jogador fazer seu jogo. E como, às vezes, a arte serve ao cálculo, o rito funciona como o pano que cai para ocultar o ator que esqueceu sua fala que modificaria, para melhor, o cenário: ele torce o assunto para fugir de um tema delicado, oferece um café para mudar um diálogo que não estava no roteiro que previra, começa a fazer um cigarro de palha quando a proposta recém-apresentada pelo parceiro gasta cálculo mais lento, conta um caso passado há anos - aparentemente sem propósito, mas finalizado com boa lição moral para a situação presente - no momento em que o negócio está chegando ao desenlace para aumentar a tensão do parceiro e fazê-lo aluir mais ligeiro; ou sugere, com infinita sutileza, que sabe por que o outro deseja o bem que adquire, para mostrar que domina os resultados da catira.

Nos sítios, a troca de bens é constante, diversificada e, possivelmente, muito mais negociada do que nos grandes mercados; é regulada por uma gama variada de regras e avaliações objetivas e subjetivas. Os termos das trocas são abertos num leque tão amplo quanto a variedade de bens que se troca, porque nas catiras a necessidade e o cálculo individuais são referências muito objetivas. Lidando com tantas trocas e dominando um varejo extenso - como notava Kautsky -, os sitiantes ganham um insuspeitado conhecimento de mercados, preços e oportunidades. Mas negociar não é apenas um meio para conseguir bens materiais, serve também para confirmar laços, refazer acordos e complementar necessidades; é um meio de tornar os homens iguais, tanto porque eles se encaram olho-no-olho - e a medida do homem será dada por sua capacidade de enfrentar o outro -, como porque a circularidade das trocas tende a equilibrar os ganhos.

Por isso nos sítios tudo está para negócio "menos a mulher e os meninos", gostava de res- salvar Donizete, dos Bernardinos, da Chapada do Doce, em Moema -, se o negócio está em acordo com o cálculo. Assim, cresce a massa de bens, de estoques e animais, e sempre parece que isto vem do fato de que alguns bens e a própria terra gozam da capacidade de se valorizar sem a mediação do esforço humano. O progresso material pode ser percebido no decorrer da vida de uma família, mas nunca aparece em estatísticas porque os censos registram apenas fragmentos, fotogramas, dessas vidas, e porque o jogo redistributivo da herança sempre recoloca o filho no ponto em que o pai partira. Ao longo dos anos, os bens multiplicam-se nas mãos de quem sabe o momento certo de dispor, por exemplo, de um fusca para adquirir uma nesguinha de terra.

Tudo sempre é bom para uma barganha, mas o gado bovino, conforme Totonho Alves, sitiante do Capivari dos Macedos, Bom Despacho, é o "mais principal", o melhor, mesmo, para converter bens, mercadorias e dinheiro. Solto nos pastos, rende por si: medeia negócios, é líquido, é meio de produção, aumenta, pode ser estocado, fracionado, reunido, cedido à meia e, até, alugado - uma inovação criada por alguns produtores de leite do Oeste mineiro quando querem ir passar uns dias pagando promessas no santuário católico de Aparecida do Norte, em São Paulo. Por isso os sitiantes gostam de manter parte do patrimônio em gado, que é garantia sólida na inflação alta e no juro baixo, além de ser quasemoeda, pois, na definição exata de Estevão Dias, da Fazenda Pica-pau, de Miradouro: "Gado é dinheiro andando".

As reses não se enquadram muito nos padrões do mercado formal, pois o gado raramente é terminado, isto é, nunca chega às 16 arrobas convencionadas para o abate. Selecionam as fêmeas por juventude, rusticidade e habilidade materna; importa menos a produtividade leiteira. Essa cultura que envolve o rebanho territorializa sua liquidez, mas não a elimina, ou seja, há sempre um ajustamento de preço às demandas do mercado nacional, ao menos em parte. A criação é orientada para reprodução, troca e reserva de valor:

Estou criando estas novilhas e esperando elas para leite. Mas elas estão para negócio, ou se 
apertar a gente negocia. Os garrotes também são para recria, mas se apertou a gente vende e se aparecer negócio a gente faz. Para ver: eu estava devendo meu cunhado. Ele veio, olhou um gado e ficou com ele pela dívida. Sempre tem um aperto de pasto, um aperto de dinheiro, vende um garrote para comprar um adubo de café, estamos sempre vendendo ou trocando (Ivo Almeida, sitiante do Oeste de Minas Gerais).

Mas, antes de tudo, gado é um meio para adquirir terra. A terra "cria" o gado, que é trocado por mais gado, que, recriado, produz mais terra. É por isso que os ganhos da migração, as sobras da panha de café, as rendas não-agrícolas e do trabalho a-dias são convertidos em gado. A sobra, o apurado, o ganhame viram gado, que, se espera, produza mais sobras, e, por fim, mais terra:

Vendi o gado e comprei a terrinha, com um sócio, e daí pra frente todo cobrinho que sai da minha mão é para comprar mais um gadinho. A gente faz é fundo [gado pior] e cabeceira [gado melhor], mas vende indiferente: quer cabeceira? Vai cabeceira! Junta um café, um mantimento que sobrou, faz mais uns bezerros. Hoje mesmo, se meu sócio der de vender a parte dele, eu desfaço desse gado, que já dá para pagar. ["E fica sem gado?"] Vou refazendo, e de um capado mais uns alqueires de arroz sai mais bezerra... ["E se ele não quiser vender?"] Se for outro caso, eu desfaço das novilhas do mesmo jeito, para botar noutra coisa mais parada, noutro terreno (Estevão Dias, sitiante da Zona da Mata de Minas Gerais).

É esse cálculo demorado que o sitiante faz, avaliando as oportunidades de economizar, criar, catirar e, finalmente, adquirir terra. Quando quer partes de terras da herança comum dominada por irmão ou cunhado, o sitiante corta despesas, descobre novas receitas e catira animais para ir comprando terra aos poucos, porque quanto mais compra mais tem condição para tornar a comprar. É uma combinação de cálculo de longo prazo que avalia disponibilidades, recursos, prazos, precisões e oportunidades -, sorte - para a boa saúde do gado e da família, para que apareçam as transações que precisa fazer -, esperteza - para reconhecer a boa oportunidade, alongar os prazos e levar a cabo trocas vantajosas sem prejudicar ninguém das proximidades - e muito tra- balho - para garantir o sustento diário, fazer sobras e poder comprar mais gado.

Nessa combinação, a família forma o pecúlio ao longo do tempo. Independentemente da quantidade de bens que possui, ou chega a possuir, o estilo de aquisição e as combinações que deve fazer são as mesmas. Sempre, também, ao final de um ciclo de vida o sitiante se encontra, no máximo, no ponto em que seu pai chegara: reuniu as terras que foram partilhadas entre irmãos e cunhados, criou seus filhos e partilhou entre eles o patrimônio amealhado. Aí então o ciclo recomeçaria, mas fatores externos podem mudar a situação, como vem acontecendo desde a década de 1980 com a queda brutal da natalidade, que aumentou a legítima dos herdeiros ao reduzir a partilha e reduziu o monte-mór com a diminuição da massa de trabalho-sobrante que seria estocada pela família do fim da infância ao início da idade adulta dos muitos filhos. Além disso, a universalização das aposentadorias e das pensões rurais e a quase generalização do acesso aos recursos de programas compensatórios contribuíram para inverter o padrão histórico de dependência e reprodução entre gerações e gêneros, ao tornar os idosos mais líquidos do que os adultos jovens e as mulheres mais endinheiradas do que os homens.

No entanto, a lógica permanece. Com bolsas e pensões, aposentadorias e transferências, os sitiantes vão adquirindo e trocando porcos por gado, produtos por animais, animais por equipamentos, e vice-versa, e, quando é preciso, tudo por dinheiro, e novamente por gado, e finalmente por mais terra. Com efeito, o rumo das trocas não muda: machos por fêmeas, adultos por jovens, poucos por muitos, semoventes por mais parados.

Nas regiões mineiras onde as trocas são mais fortes, sitiantes podem até se tornar, em definitivo ou por uns tempos, catireiros profissionais. Esses lidam a maior parte das vezes com vacas ou bezerros descartados e fazem seus negócios com prazos estabelecidos. São muito úteis porque dão um destino ao bezerro - o macho imprestável no rebanho leiteiro especializado -, à vaca de fundo e, ao mesmo tempo, um pecúlio aos sitiantes. A atividade vai ocupar muito do seu tempo: trocam ou compram pequenos lotes, às vezes refazem o gado em bons pastos para barganhar mais adiante 
por bens ou outro gado e muitas vezes reúnem uma bezerrada macha para negociar com invernistas que carecem de gado macho, jovem e magro para terminar e levar ao abate. Catireiros são elos ativos nessa cadeia produtiva torta que leva gado sem serventia nos sítios para a ponta da terminação ou do consumo. ${ }^{8}$

Catireiro tem que ser conhecido, ter bens próprios e sua rede de informantes; tem que saber onde existe algum gado, animal ou bem para ser barganhado e, também, onde há alguém interessado naquilo que ele tem ou que pode adquirir. Mas, sobretudo, precisa ter um bom nome: "Catireiro não prospera com embondo [logro ou embaraço]", resumia Jarico Rodrigues, do Paranaíba, ele mesmo um raro sitiante que adquiriu mais terra do que a herança paterna às custas de muito trabalho e maestria na catira.

Os catireiros dependem desse bom nome, pois com isso podem até mesmo fazer negócio sem ter capital, na base apenas da confiança e dos prazos. Eles dizem que os prazos "dão os seus dias" - "prazo, um dia, vence...", assegura Valtervi, sitiante do Capivari dos Macedos. Mas enquanto os prazos correm por um lado, os catireiros rodeiam pelo outro lado para produzir bens ou dinheiro que seus compromissos exigem. Por isso o tempo e as informações sobre o seu mercado são essenciais: para ver um animal, saber de precisões dos outros, esperar novidades. Parece que o bom catireiro não trabalha, que tem a vida inteira à sua disposição. Gasta tempo se informando sobre preços nos mercados nacionais, sobre os apertos de dinheiro do produtor, sobre seus planos e interesses, enfim, tudo o que vale saber sobre a vida alheia. Mas finge não saber: por exemplo, vai ao sítio procurando porcos para trocar por uma bicicleta, sabendo que o sitiante tem mesmo é garrotinho com precisão de vender para pagar no mês que entra parte de um terreno que comprou. O catireiro finge ser sonso, no jogo de deixar a palavra inicial do negócio ao parceiro, que, forçado a abrir a catira, revela seu teto de cálculo e fornece o galeio - o balanço do valor -, onde o catireiro se apóia para começar a desenrolar a trama de possibilidades que carrega, já há muito, na cabeça.

\section{Catiras, dons, riquezas}

O negócio da catira, como a dança da catira, tem coreografia e ritmo próprios, num e noutra só aparecem os homens. Negócio e dança formam patrimônios - semoventes, materiais, simbólicos e culturais - que dão vigor e perenidade a essas sociedades rurais que se celebram e se revelam nessas suas artes.

Mas o negócio é uma arte particular. Ligado à vida mesma de todo dia, funciona como um mecanismo que produz e ajusta a riqueza que, por sua vez, se expande das coisas para as famílias e das famílias para o lugar, porque os bens, ao circular, cimentam as bases que fundam a economia dessas regiões rurais. Por isso é que não deve haver assombro nem preconceito ao ver sitiantes, com catiras, dar nova forma material aos produtos da lavoura, da migração, da pluriatividade, das aposentadorias e de outros meios de aquisição de renda.

Essas habilidades e costumes, porém, são recebidos com certo desrespeito por parte de técnicos e especialistas em desenvolvimento rural. Os mais puristas garantem ser inútil esse conhecimento que sitiantes têm do mercado - costuma ser dito assim mesmo, como se fosse um ente único -, uma vez que esse tipo de lógica de sobrevivência e reprodução só lhes traz prejuízos, como, por exemplo, trocar dinheiro por bens imóveis e esterilizar investimentos, barganhar uma safra por novilhas de sobre-ano e estar sempre montando e refazendo gados para, ao termo, convertê-los em bens "mais parados". Os sitiantes careceriam de cursos, de conhecer os meandros da circulação das mercadorias, dos preços e das finanças, para se tornarem, enfim, devedores prósperos e empreendedores ativos.

Grande engano, pois as catiras são essenciais para a reprodução dessas famílias e dos regimes agrários. Dinamizam grandes e pequenos negócios, agilizam a circulação de bens, criam e distribuem riquezas, consolidam poupanças, expandem o patrimônio comercial ao firmar relações costumeiras de confiança que alicerçam novas e continuadas trocas entre os agentes econômicos. Criam, portanto, estabilidade na economia rural ao criar oportunidades para muitos. Isso fica evidente na força do pequeno comércio e indústria familiar 
ao longo da rota Centro Oeste-Triângulo Mineiro, na demorada estabilidade econômica da Zona da Mata mineira, na diversificação das atividades rurais e urbanas dos pequenos municípios do Alto Paranaíba. Nessas regiões de base agrária familiar, de boa pecuária e catira forte, dia-a-dia os sitiantes refazem seus negócios e dão fôlego às suas trajetórias tão iguais e diversas que conformam o campo do país dos mineiros.

\section{Notas}

1 As categorias de uso local virão em itálico na sua primeira aparição neste artigo.

2 Para análise dessas estratégias, ver Garcia (1984), Garcia Jr. (1989), Schneider (2001) e Abramovay (2004). Um estudo clássico sobre o lugar da família na estratégia de reprodução foi realizado por Chayanov (1974).

3 A esse respeito consultar Lovisolo (1989) sobre sociedades camponesas; Teixeira da Silva (1997) sobre fazendas; Queiroz (1997) sobre o Sul do Brasil; Ribeiro (1998) sobre o Sudeste; Andrade (1986) sobre o Nordeste. Para estudos mais antigos consultar Santos Filho (1957) e mais recentes, ver Schröder (2004). Como o animal é um bem que resulta da ação combinada da natureza e do trabalho, não possui o caráter perverso e usurário da moeda. Sobre a imagem espúria do dinheiro nas sociedades camponesas, consultar Martins (1981) e Woortmann (1987).

4 Esses sitiantes produzem leite, matrizes leiteiras e recriam machos, que vendem junto com vacas de descarte; criam mais gado que seus pastos suportam e as vacas lactantes correspondem a menos de um terço dos rebanhos (Sebrae, 1996; Ufla, 1997).

5 A diferença entre o terceiro e o último tipo de aquisição é grande, pois irmãos(ãs) ou cunhados(as) tendem a vender terras com preços e prazos favorecidos, e muitas vezes os negócios são casados, isto é, vendem as suas glebas para comprar terras de outros parentes. A esse respeito, ver Moura (1978).

6 Mulheres costumam vender produtos, mas quase nunca fazem negócios como as catiras. Osório Dudu, sitiante da Vereda das Araras, no rio Acari, ao Norte, explica que "juízo de mulher [para barganhas] só dura até o meio-dia”.
7 O senhor Abel, sitiante de São Gotardo, contou, por exemplo, que o vizinho avisou que "vinha catirar a charrete, p'r'eu pensar que ele queria dois garrotinhos [novilhos]; mas eu sei que ele queria mesmo é o cavalinho, porque está sem animal para puxar [transportar] leite". Barganharam o cavalinho por três arrobas de café, uma leitoa e Cr\$ 1.000,00 em quarenta dias.

8 Em Bom Despacho há um lugar onde os catireiros ficam esperando negócios; essa banca de trabalho é apelidada de Catiródromo.

9 Catireiros cumprem seus acordos mesmo que isso signifique sua própria falência. Um deles, em São Gotardo, adquiriu bezerros e os vendeu para um frigorífico que faliu; vendeu a herança da esposa o bem que lhes restara -, mas não deixou de honrar seus compromissos; pagou as dividas e seguiu catirando com os parceiros de sempre.

\section{BIBLIOGRAFIA}

ABRAMOVAY, R. (2004), Laços financeiros na luta contra a pobreza. São Paulo, Annablume/Fapesp.

ALMEIDA, A. W. B. de. (1988), "Terra de preto, terra de santo, terra de índio: uso comum e conflito". Humanidades, ano IV (15): 42-58, Brasília, UnB.

AMARAL, L. (1988), Do Jequitinhonha aos canaviais. Dissertação de mestrado, Belo Horizonte, UFMG, Fafich.

ANDRADE, M. C. (1986), Terra e bomem no Nordeste. São Paulo, Brasiliense.

BRANDÃO, C. R. (1981), Plantar, colher, comer. Rio de Janeiro, Graal.

CARVALHO FRANCO, M. S. (1974), Homens livres na ordem escravocrata. São Paulo, Ática.

CHAYANOV, A. V. (1974), La organización de la unidad económica campesina. Buenos Aires, Nueva Visión.

GALIZONI, F. M. (2002), "Terra, ambiente e herança no alto Jequitinhonha". Revista de Economia e Sociologia Rural, 40 (3): 175-201. 
GARCIA JR., A. R. (1989), O sul, caminho do roçado. São Paulo, Marco Zero.

GARCIA, M. F. (1984), Feira e trabalhadores rurais. Tese de doutorado, UFRJ/PPGAS.

GODOY, E. P. (1998), "O sistema do lugar", in A. M. Niemeyer e E. P. Godoy, Além dos territórios, Campinas, Mercado de Letras.

HEREDIA, B. A. (1979), A morada da vida. Rio de Janeiro, Paz e Terra.

KAUTSKY, K. (1972), A questão agrária. Tradução de J. Antunes. Porto, Portucalense.

LOVISOLO, H. R. (1989), Terra, trabalho e capital. Campinas, Edunicamp.

MARTINS, J. S. (1981), Os camponeses e a politica no Brasil. Petrópolis, Vozes.

MAUSS, M. (1988), Ensaio sobre a dádiva. Tradução de A. F. Marques. Lisboa, Edições 70.

MOURA, M. M. (1978), Os herdeiros da terra. São Paulo, Hucitec.

QUEIROZ, M. V. (1977), Messianismo e conflito social. 2 ed. São Paulo, Ática.

RIBEIRO, E. M. (1998), "Vaqueiros, bois e boiadas: trabalho, negócio e cultura na pecuária do Nordeste mineiro". Estudos Sociedade e Agricultura, 11: 135-163.

SANTOS, J. V. T. (1978), Os colonos do vinho. São Paulo, Hucitec.

SANTOS FILHO, L. (1957), Uma comunidade rural no Brasil antigo. São Paulo, Companhia Editora Nacional.

SCHNEIDER, S. (2001), "A pluriatividade como estratégia de reprodução social da agricultura familiar no Sul do Brasil". Estudos Sociedade e Agricultura, 16: 48-75.

SCHRÖDER, M. (2004), "As demandas financeiras dos agricultores do sertão do Pajeú", in R. Abramovay (org.), Laços financeiros na luta contra a pobreza, São Paulo, Annablume/Fapesp.
SCHULTZ, T. W. (1965), A transformação da agricultura tradicional. Tradução de J. A. T. Rocha. Rio de Janeiro, Zahar.

SEBRAE. (1996), "Relatório de pesquisa: diagnóstico da pecuária leiteira do estado de Minas Gerais". Belo Horizonte, Sebrae/FAEMG

TEIXEIRA DA SILVA, F. C. (1997), "Pecuária e formação do mercado interno no Brasilcolônia". Estudos Sociedade e Agricultura, 8: 20-56.

UFLA/COOPERBOM. (1997), "Produtor e produção de leite: perfil dos associados da Cooperbom". Relatório de Pesquisa, Lavras/Bom Despacho, Faepe/Cooperbom.

WOORTMANN, K. (1987), "Com parente não se neguceia": o campesinato como ordem moral. Anuário Antropológico, Brasília, Editora da UnB/Tempo Brasileiro, pp. 11-73.

WOORTMANN, K. (1990), "Migração, família e campesinato". Revista Brasileira de Estudos de População, 7: 35-53. 


\section{A ARTE DA CATIRA: NEGÓ- CIOS E REPRODUÇÃO FAMI- LIAR DE SITIANTES MINEIROS \\ THE ART OF CATIRA: BUSI- NESS AND REPRODUCTION OF SMALL FARM FAMILIES OF MINAS GERAIS}

Eduardo Magalhães Ribeiro Flávia Maria Galizoni

\section{Palavras-chave}

Agricultura familiar; Estratégias de reprodução; Extensão rural; Reciprocidade; Minas Gerais.

Este artigo analisa os negócios costumeiros de sitiantes de Minas Gerais, as catiras, investigando porque se empenham nessas transações, quais destinos dão aos ganhos que obtém, e como constroem sólidas redes de trocas baseadas em relações de confiança. Assim formam, aos poucos, importantes patrimônios materiais e simbólicos. Esse movimento econômico local, regido por regras próprias e articulado perifericamente aos mercados nacionais, é vital para as suas estratégias de reprodução, para gerar, conservar e ampliar os patrimônios. A lógica peculiar dessas trocas explica vários procedimentos, que geralmente são considerados pouco racionais por técnicos e pesquisadores, mas que fazem parte de muitos cálculos, levados a cabo por anos, para ampliar o pecúlio da família.
Eduardo Magalhães Ribeiro Flávia Maria Galizoni

\section{Keywords}

Family agriculture; Reproduction strategies; Rural extension; Minas Gerais.

This article analyzes the usual businesses of small landholders of Minas Gerais, the so-called "catiras", investigating why they insist on these transactions, the destination given to the earnings that they obtain, and how they construct solid exchange networks based on trust relationships. Through these they steadily form important material and symbolic patrimonies. This local economic movement, governed by its own rules and peripherally articulated to national markets, is vital for their reproduction strategies, as well as to generate, conserve, and enlarge their patrimonies. The peculiar logic of those exchanges explains several procedures, which are usually considered by technicians and researchers as a little irrational, although they are part of many calculations, firmly employed for years to enlarge the families' savings.
L'ART DE LA CATIRA: AFFAIRES ET REPRODUCTION FAMILIALE DES PAYSANS DE L'ÉTAT DE MINAS GERAIS

Eduardo Magalhães Ribeiro Flávia Maria Galizoni

\section{Mots-clés}

Agriculture familiale; Stratégies de reproduction; Extension rurale; Minas Gerais.

Cet article analyse les affaires coutumières des paysans de Minas Gerais, les catiras, en cherchant les raisons pour lesquelles ils s'intéressent à ces transactions, quelle est la destination de leurs gains et comment ils construisent un réseau solide d'échanges basé sur des relations de confiance. Ils ont, ainsi, peu à peu, formé des patrimoines matériels et symboliques. Ce mouvement économique local, régi par des règles propres et lié aux marchés nationaux, est vital par ses stratégies de reproduction pour produire, conserver et agrandir les patrimoines. La logique particulière de ces échanges explique plusieurs conduites qui sont généralement considérées peu rationnelles par les spécialistes et chercheurs, mais qui font partie de nombreux calculs développés au long de plusieurs années pour augmenter le capital de la famille. 